\title{
Article \\ Physiological and Gene Expression Responses of Six Annual Ryegrass Cultivars to Cobalt, Lead, and Nickel Stresses
}

\author{
Siyu Qiao ${ }^{1, \dagger}$, Ye Tao ${ }^{1, \dagger}$, Qinghua Shan ${ }^{1}$, Jingang Wang ${ }^{1}$, Tuanyao Chai ${ }^{2}$, Shufang Gong ${ }^{1, *}$ and Kun Qiao ${ }^{1, *}$ \\ 1 College of Horticulture and Landscape Architecture, Northeast Agricultural University, \\ Harbin 150030, China; siyuqiao1997@163.com (S.Q.); ty18646408777@163.com (Y.T.); \\ sqh19971001@163.com (Q.S.); wangjingang99@neau.edu.cn (J.W.) \\ 2 College of Life Science, University of Chinese Academy of Sciences, Beijing 100049, China; tychai@ucas.ac.cn \\ * Correspondence: shufanggong@neau.edu.cn (S.G.); kunqiao@neau.edu.cn (K.Q.) \\ + These authors have equally contributed to the work.
}

check for updates

Citation: Qiao, S.; Tao, Y.; Shan, Q.; Wang, J.; Chai, T.; Gong, S.; Qiao, K. Physiological and Gene Expression Responses of Six Annual Ryegrass Cultivars to Cobalt, Lead, and Nickel Stresses. Int. J. Mol. Sci. 2021, 22, 13583. https://doi.org/10.3390/ ijms222413583

Academic Editors: Luigi De Bellis and Alessio Aprile

Received: 25 November 2021 Accepted: 15 December 2021 Published: 18 December 2021

Publisher's Note: MDPI stays neutral with regard to jurisdictional claims in published maps and institutional affiliations.

Copyright: (c) 2021 by the authors. Licensee MDPI, Basel, Switzerland. This article is an open access article distributed under the terms and conditions of the Creative Commons Attribution (CC BY) license (https:// creativecommons.org/licenses/by/ $4.0 /)$.

\begin{abstract}
Heavy metals negatively affect soil quality and crop growth. In this study, we compared the tolerance of six ryegrass cultivars to cobalt $\left(\mathrm{Co}^{2+}\right)$, lead $\left(\mathrm{Pb}^{2+}\right)$, and nickel $\left(\mathrm{Ni}^{2+}\right)$ stresses by analyzing their physiological indexes and transcript levels of genes encoding metal transporters. Compared with the other cultivars, the cultivar Lm1 showed higher germination rates and better growth under $\mathrm{Co}^{2+}, \mathrm{Pb}^{2+}$, or $\mathrm{Ni}^{2+}$ treatments. After $48 \mathrm{~h}$ of $\mathrm{Co}^{2+}$ treatment, the total antioxidant capacity of all six ryegrass cultivars was significantly increased, especially that of Lm1. In contrast, under $\mathrm{Pb}^{2+}$ stress, total antioxidant capacity of five cultivars was significantly decreased, but that of Lm1 was unaffected at $24 \mathrm{~h}$. Staining with Evans blue dye showed that the roots of Lm1 were less injured than were roots of the other five ryegrass cultivars by $\mathrm{Co}^{2+}, \mathrm{Pb}^{2+}$, and $\mathrm{Ni}^{2+}$. $\mathrm{Lm} 1$ translocated and accumulated lesser $\mathrm{Co}^{2+}, \mathrm{Pb}^{2+}$, and $\mathrm{Ni}^{2+}$ than other cultivars. In $\mathrm{Lm} 1$, genes encoding heavy metal transporters were differentially expressed between the shoots and roots in response to $\mathrm{Co}^{2+}$, $\mathrm{Pb}^{2+}$, and $\mathrm{Ni}^{2+}$. The aim of these researches could help find potential resource for phytoremediation of heavy metal contamination soil. The identified genes related to resistance will be useful targets for molecular breeding.
\end{abstract}

Keywords: ryegrass; $\mathrm{Co} / \mathrm{Pb} / \mathrm{Ni}$ tolerance; physiological indexes; gene expression

\section{Introduction}

Heavy metals come from both the natural environment and human activities [1] Heavy metal contaminants in soil are derived from traffic emissions (automobile exhaust, fuel combustion, tire wear particles), industrial emissions (mining of mineral resources, metal processing and smelting, coal combustion), and agricultural emissions (sewage irrigation and pesticide sprays) [2,3]. Common heavy metals are not naturally degraded and accumulate continuously in the environment. They pose a serious threat to human health and food security $[4,5]$.

Some heavy metals such as cobalt (Co), nickel (Ni), manganese (Mn), zinc ( $\mathrm{Zn})$, copper $(\mathrm{Cu})$, and iron $(\mathrm{Fe})$ are essential micronutrients for plants. Cobalt plays an important role in plant growth and development. It is related not only to pigmentation in the leaves of legumes, but also the production of secondary metabolites, such as betaine [6]. However, excess Co in plants can disrupt many physiological, biochemical, and metabolic processes. Nickel is also an essential microelement for plant growth and development. It is a component of several enzymes (e.g., glyoxalase and urease) required for nitrogen metabolism, and plays an important role in nitrogen assimilation. Moreover, Ni can enhance the activity of various enzymes, and participate in resistance to abiotic stress. Therefore, Ni-deficient plants show symptoms, such as growth retardation and reduced nitrogen metabolism and iron absorption [7-9]. However, excess Ni can reduce the seed 
germination rate, negatively affect photosynthesis and respiration, and cause yellowing and necrosis of the leaves [10].

Lead $(\mathrm{Pb})$ is a non-essential element in plants. It can inhibit seed germination and plant growth. Excess $\mathrm{Pb}$ can directly inhibit leaf development and the elongation of stems and roots [11]. It also affects glucose metabolism and stimulates the oxidation of indole-3 acetic acid. Consequently, $\mathrm{Pb}$ negatively affects plant growth, biomass, and cell growth [12].

Annual ryegrass (Lolium multiflorum Lam.) is a widely distributed good-quality forage grass, and it can be used as an indicator plant in heavy metal-contaminated environments [13]. Compared with white clover and alfalfa, annual ryegrass is more tolerant to $\mathrm{Cd}$ [14]. Compared with Cd-sensitive cultivars, the more Cd-tolerant ryegrass cultivars accumulate and transport less Cd [15]. However, little is known about the effects of other heavy metals, including $\mathrm{Co}^{2+}, \mathrm{Pb}^{2+}$, and $\mathrm{Ni}^{2+}$, on gene expression and the growth and development of annual ryegrass cultivars.

In this study, we analyzed physiological parameters of six ryegrass cultivars treated with $\mathrm{Co}^{2+}, \mathrm{Pb}^{2+}$, or $\mathrm{Ni}^{2+}$, and determined changes in the transcript levels of genes encoding heavy metal transporters. As a preliminary analysis of the effects of these heavy metals on ryegrass, we determined the relative inhibition rate of germination, relative inhibition rate of shoot length, and relative inhibition rate of root length of six ryegrass cultivars treated with solutions of $\mathrm{Co}^{2+}, \mathrm{Pb}^{2+}$, or $\mathrm{Ni}^{2+}$. The effects of these heavy metals on root cell survival were determined using Evan's blue staining. We determined the total antioxidant capacity of the six cultivars under $\mathrm{Co}^{2+}, \mathrm{Pb}^{2+}$, or $\mathrm{Ni}^{2+}$ stress. To analyze the uptake and translocation of heavy metals, we conducted milestone microwave digester and inductively coupled plasma mass spectrometry (ICP-MS) analyses to determine the contents of heavy metals in roots and shoots. The effects of $\mathrm{Co}^{2+}, \mathrm{Pb}^{2+}$, and $\mathrm{Ni}^{2+}$ treatments on the transcript levels of genes encoding heavy metal transporters were determined by RT-qPCR. The results of this study will be useful for identifying hyperaccumulator ryegrass varieties to phytoremediate soils contaminated with heavy metals. In addition, genes related to resistance will be useful targets for selective and molecular breeding strategies.

\section{Results}

\subsection{Effects of $\mathrm{Co}^{2+}, \mathrm{Pb}^{2+}$, and $\mathrm{Ni}^{2+}$ on Growth of Six Ryegrass Cultivars}

As the $\mathrm{Co}^{2+}$ concentration increased, the germination of the six ryegrass cultivars gradually decreased (Figure 1). As shown in Figure 1a and Figure S1, the germination of Lm2, Lm3, Lm4, Lm5, and Lm6 were inhibited by the $200-500 \mathrm{mg} / \mathrm{L} \mathrm{CoCl}_{2}$ treatments, but that of $\mathrm{Lm} 1$ was unaffected. In the $2000 \mathrm{mg} / \mathrm{L} \mathrm{CoCl}_{2}$ treatment, the relative inhibition rate of germination of Lm1 was 10\%, which was significantly lower than those of the other ryegrass cultivars.
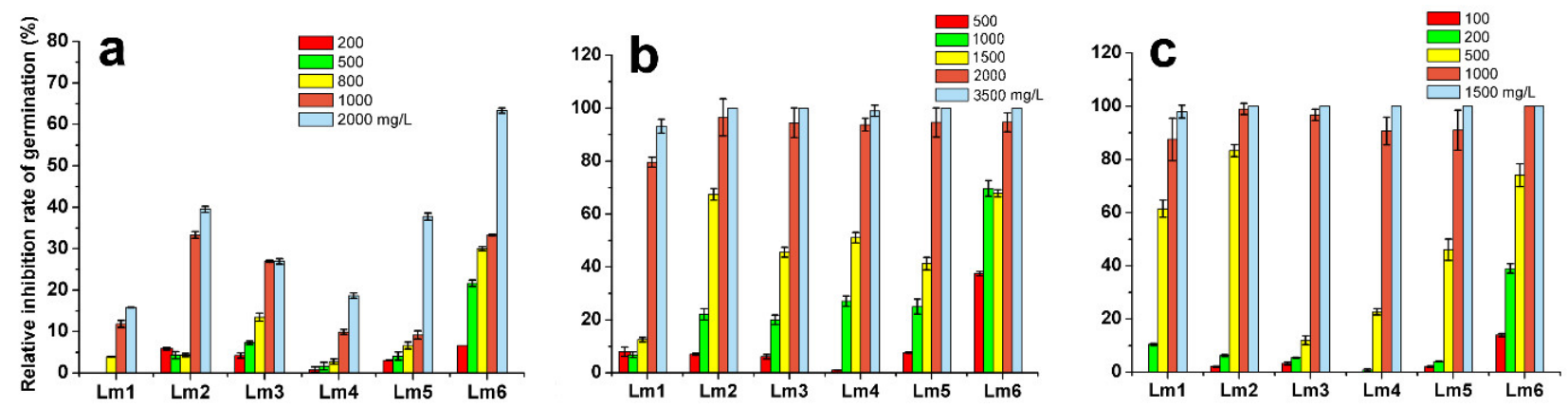

Figure 1. Relative inhibition rate of germination of six ryegrass cultivars under different concentrations of $\mathrm{Co}^{2+}, \mathrm{Pb}^{2+}$, and $\mathrm{Ni}^{2+}$. The ryegrass seeds were germinated for $5 \mathrm{~d}$ on sterile filter paper containing different concentrations of $\mathrm{Co}(\mathbf{a}), \mathrm{Pb}(\mathbf{b})$, and $\mathrm{Ni}$ (c). $\mathrm{CoCl}_{2}$ concentrations: 0, 200, 500, 800, 1000, $2000 \mathrm{mg} / \mathrm{L} ; \mathrm{Pb}\left(\mathrm{NO}_{3}\right)_{2}$ concentrations: 0, 500, 1000, 1500, 2000, and $3500 \mathrm{mg} / \mathrm{L} ; \mathrm{NiSO}_{4}$ concentrations: 0, 100, 200, 500, 1000, and $1500 \mathrm{mg} / \mathrm{L}$. The plates were divided into four zones, each with 25 seeds. 
The $\mathrm{Pb}$ treatments significantly inhibited the germination of all six ryegrass cultivars (Figure 1b, Figure S2). Notably, the relative inhibition rate of germination was lower in $\mathrm{Lm} 4$ than in the other cultivars in the $500 \mathrm{mg} / \mathrm{L} \mathrm{Pb}$ treatment, and the relative inhibition rate of germination of Lm1 was significantly lower than that of other cultivars in the 1000-1500 mg/L Pb treatments. In the $3500 \mathrm{mg} / \mathrm{L} \mathrm{Pb}$ treatment, seed germination was completely inhibited in all cultivars.

The relative inhibition rate of germination was lower for Lm1 than for the other cultivars in the treatments with lower concentrations of Ni (Figure 1c, Figure S3). However, as the Ni concentration increased, the relative inhibition rate of germination of Lm1 enhanced, and was not significantly different from those of the other cultivars in the $200-1500 \mathrm{mg} / \mathrm{L}$ Ni treatments.

\subsection{Effects of $\mathrm{Co}^{2+}, \mathrm{Pb}^{2+}, \mathrm{Ni}^{2+}$ on Physiological Indexes of Six Ryegrass Cultivars}

To understand the variations in heavy metal tolerance among the six ryegrass cultivars, we determined the relative inhibition rates of shoot length and root length of each cultivar under $\mathrm{Co}^{2+}, \mathrm{Pb}^{2+}$, or $\mathrm{Ni}^{2+}$ stress. The relative inhibition rate of shoot length of $\mathrm{Lm} 1$ was significantly lower than those of the other cultivars in the 200 to $1000 \mathrm{mg} / \mathrm{L} \mathrm{CoCl}_{2}$ treatments (Figure 2a-g). The relative inhibition rate of root length was also slightly weaker in $\mathrm{Lm} 1$ than in the other cultivars in the 200 to $1000 \mathrm{mg} / \mathrm{L} \mathrm{CoCl}_{2}$ treatments. However, root growth was almost completely inhibited in the $2000 \mathrm{mg} / \mathrm{L} \mathrm{CoCl}_{2}$ treatment (Figure $2 \mathrm{~h}$ ).

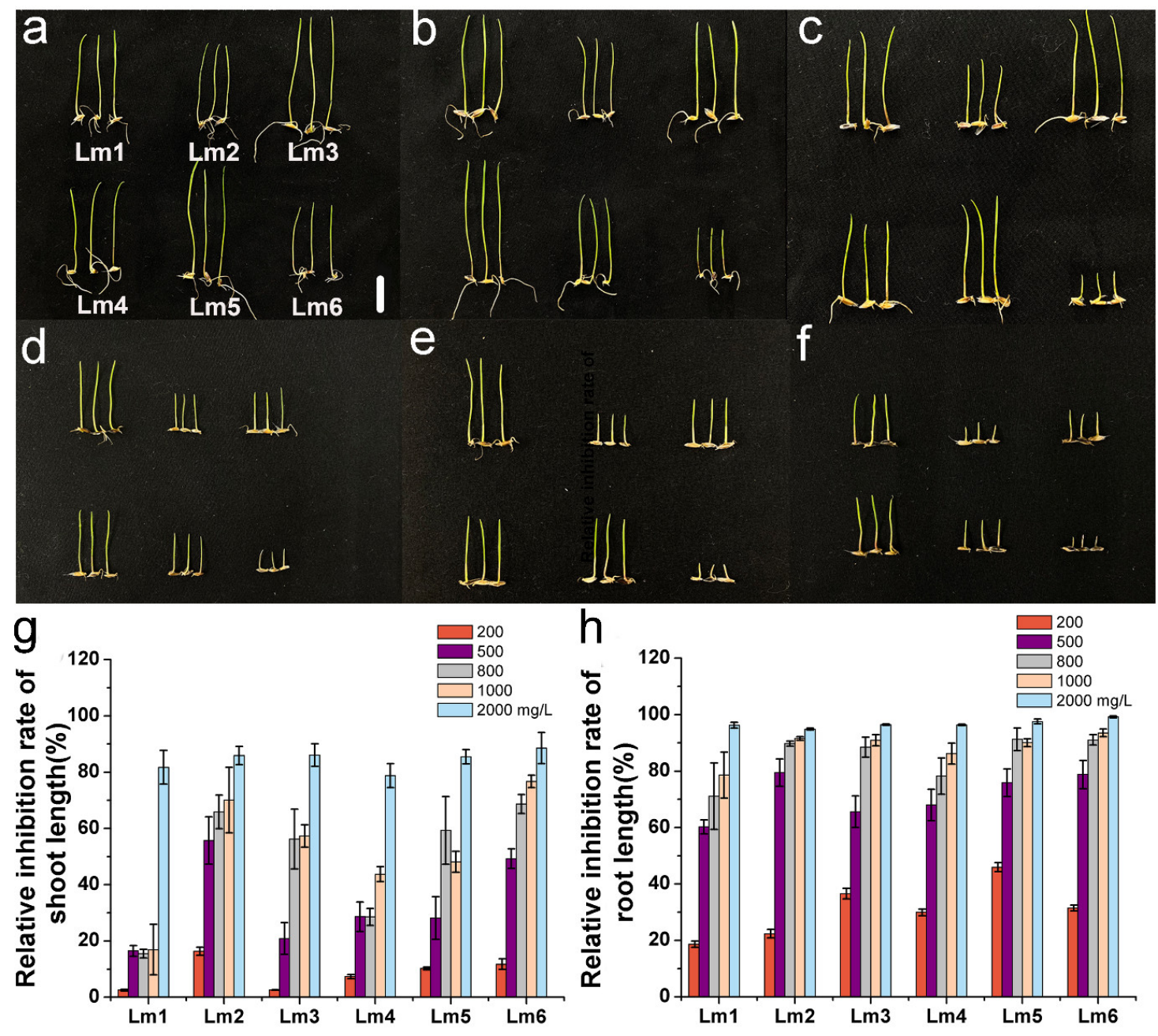

Figure 2. Phenotypic analysis of six ryegrass cultivars treated with different $\mathrm{Co}^{2+}$ concentrations. All seeds were germinated with 0 (a), 200 (b), 500 (c), 800 (d), 1000 (e), and $2000 \mathrm{mg} / \mathrm{L}$ (f) $\mathrm{CoCl}_{2}$. Growth was observed and photographed, and relative inhibition rate of shoot length $(\mathrm{g})$, and relative inhibition rate of root length $(\mathbf{h})$ were analyzed at $6 \mathrm{~d}$. Scale bars: $10 \mathrm{~mm}$. 
In the $\mathrm{Pb}$ treatments, the relative inhibition rate of shoot length was weaker in Lm1 than in the other cultivars in the 1000 to $1500 \mathrm{mg} / \mathrm{L} \mathrm{Pb}$ treatments (Figure 3a-g). The root growth of cultivars was all inhibited by $\mathrm{Pb}$ stress, and the relative inhibition rates of root length was not significantly different among the six ryegrass cultivars (Figure $3 \mathrm{~h}$ ). The seed germination of Lm5 was completely inhibited (Figure 3f).
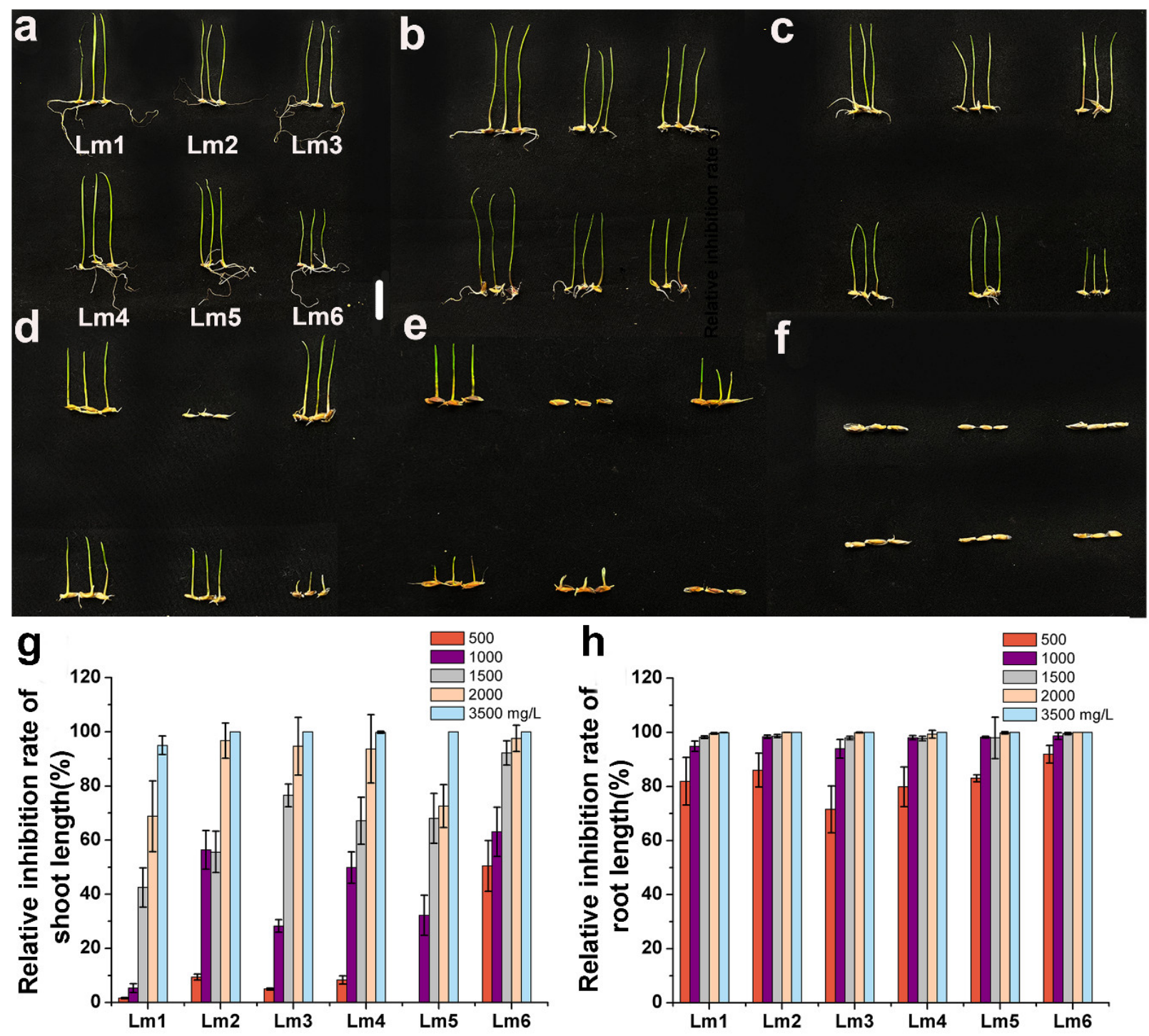

Figure 3. Phenotypic analysis of six ryegrass cultivars treated with $\mathrm{Pb}\left(\mathrm{NO}_{3}\right)_{2}$ at 0 (a), 500 (b), 1000 (c), 1500 (d), 2000 (e), and 3500 (f) $\mathrm{mg} / \mathrm{L}$. All seeds were germinated with different concentrations of $\mathrm{Pb}\left(\mathrm{NO}_{3}\right)_{2}$. Growth was observed and photographed $(\mathbf{a}-\mathbf{f})$, and relative inhibition rate of shoot length $(\mathbf{g})$, and relative inhibition rate of root length $(\mathbf{h})$ were analyzed at $6 \mathrm{~d}$. Scale bars: $10 \mathrm{~mm}$.

The relative inhibition rate of shoot length of Lm1 was lower than those of the other five cultivars in the 100 and $200 \mathrm{mg} / \mathrm{L} \mathrm{NiSO}_{4}$ treatments, but significantly higher than those of Lm3, Lm4, and Lm5 in the $500 \mathrm{mg} / \mathrm{L} \mathrm{Ni}$ treatment (Figure $4 \mathrm{a}-\mathrm{g}$ ). The relative inhibition rates of root length of Lm1 were not significantly different from those of the other five ryegrass cultivars in the Ni treatments (Figure $4 \mathrm{~h}$ ).

\subsection{Effects of Heavy Metals on the Total Antioxidant Capacity of Six Ryegrass Cultivars}

The antioxidant system allows plants to remove toxic reactive oxygen species (ROS), and is often used as an indicator of plant stress resistance. The total antioxidant capacity of six ryegrass cultivars differed between the control and the heavy metal treatments. The 
total antioxidant capacity of the six cultivars was increased in response to Co treatments (Figure 5a), decreased in response to $\mathrm{Pb}$ treatments (Figure 5b), and unchanged by $\mathrm{Ni}$ treatments (Figure $5 c$ ). These findings indicated that the ryegrass cultivars might be tolerant to $\mathrm{Co}$ but sensitive to $\mathrm{Pb}$. The concentrations of $\mathrm{Ni}$ used in this experiment did not affect the total antioxidant capacity, so could not distinguish the cultivars in terms of their Ni tolerance (Figure 5).
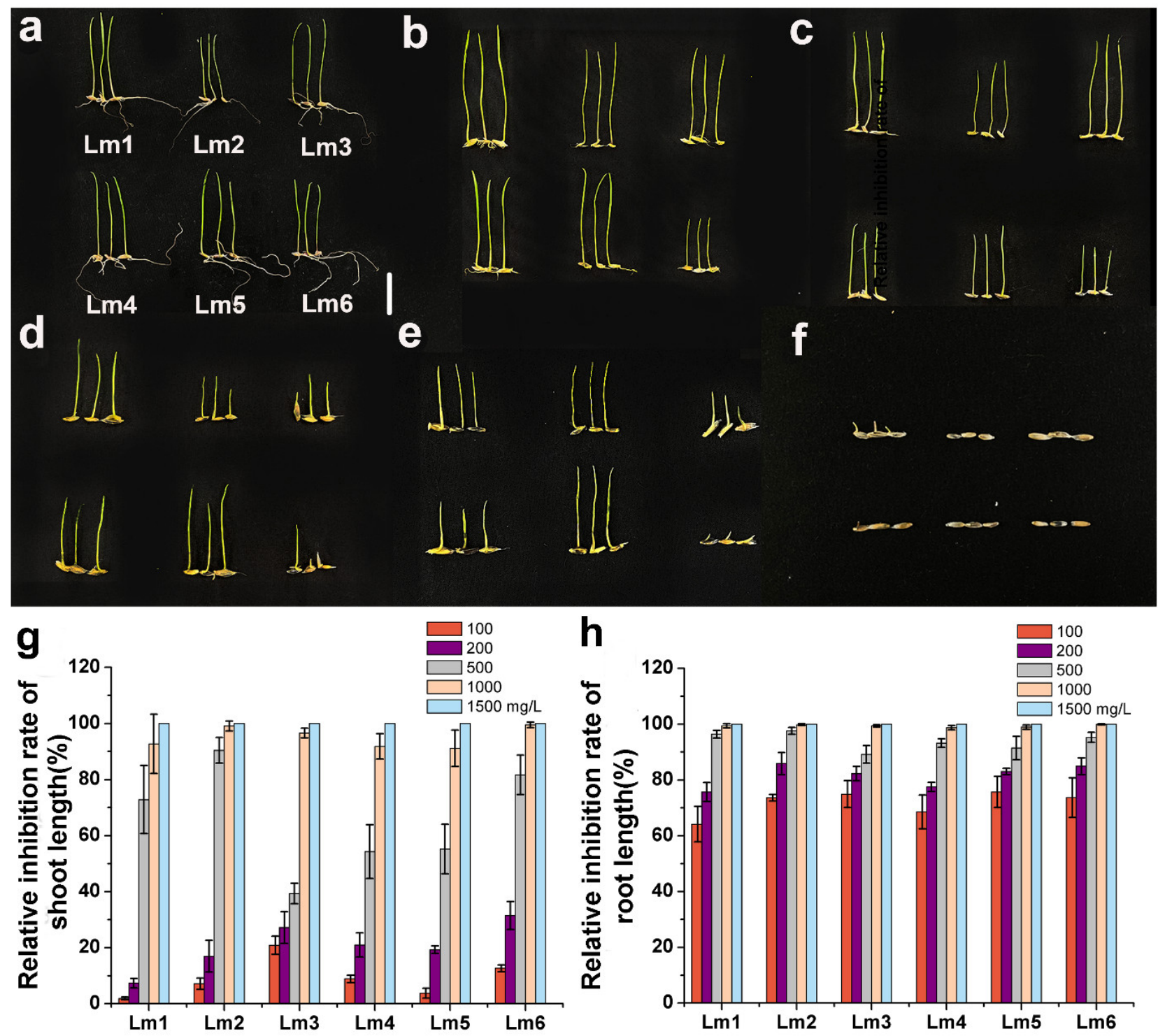

Figure 4. Phenotypic analysis of six ryegrass cultivars treated with $\mathrm{NiSO}_{4}$ at 0 (a), 100 (b), 200 (c), 500 (d), 1000 (e), and 1500 (f) $\mathrm{mg} / \mathrm{L}$. All seeds were germinated with different concentrations of $\mathrm{NiSO}_{4}$. Growth was observed and photographed (a-f), and relative inhibition rate of shoot length $(\mathbf{g})$, and relative inhibition rate of root length $(\mathbf{h})$ were analyzed at $6 \mathrm{~d}$. Scale bars: $10 \mathrm{~mm}$.

\subsection{Toxicity Symptoms in Roots of Six Ryegrass Cultivars Treated with Heavy Metals}

At high concentrations, heavy metals can damage plant tissues, especially roots. To observe damage caused by heavy metals, the roots of the six ryegrass varieties were soaked in solutions containing $\mathrm{Co}^{2+}, \mathrm{Pb}^{2+}$, or $\mathrm{Ni}^{2+}$, and then stained with Evan's blue dye, which stains dead cells blue. In Lm2, Lm3, Lm4, Lm5, and Lm6, the roots treated with $\mathrm{Co}^{2+}, \mathrm{Pb}^{2+}$, or $\mathrm{Ni}^{2+}$ showed significantly stronger Evan's blue contents than did the untreated roots $(p<0.05)$. In Lm1, however, the Evan's blue contents in roots treated with heavy metals for 3 and $6 \mathrm{~h}$ were not significantly different from that in the control (Figure 6a-c). The 
staining of all cultivars' root cells was not significantly different between the $3 \mathrm{~h}$ and $6 \mathrm{~h}$ time points, with or without heavy metal treatments (Figures S4-S6).
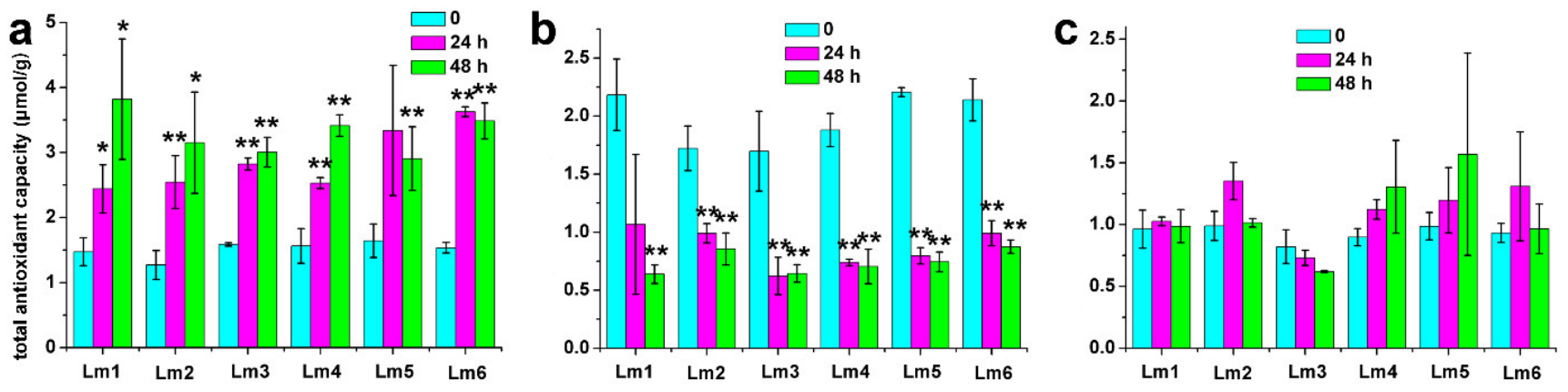

Figure 5. Total antioxidant capacity of six ryegrass cultivars treated with $\mathrm{Co}^{2+}, \mathrm{Pb}^{2+}$, or $\mathrm{Ni}^{2+}$. (a) total antioxidant capacity of six ryegrass cultivars treated with $500 \mathrm{mg} / \mathrm{L} \mathrm{CoCl}_{2} ;(\mathbf{b})$ total antioxidant capacity of six ryegrass cultivars treated with $1000 \mathrm{mg} / \mathrm{L} \mathrm{Pb}\left(\mathrm{NO}_{3}\right)_{2} ;$ (c) total antioxidant capacity of six ryegrass cultivars treated with $500 \mathrm{mg} / \mathrm{L} \mathrm{NiSO}_{4}$. Significant differences were determined by $t$-test in Excel $2010\left(^{* *} p<0.01, * 0.01<p<0.05\right)$.

a

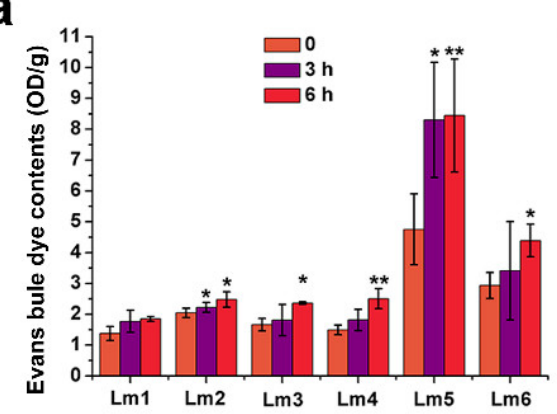

b

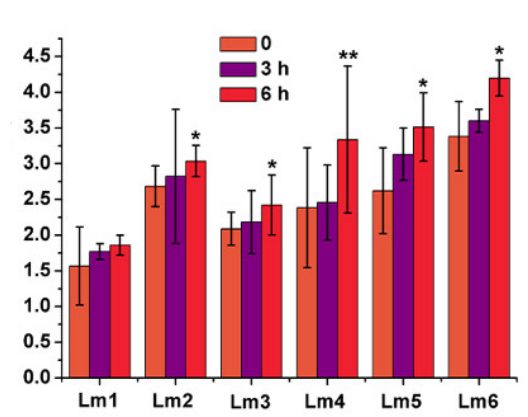

C

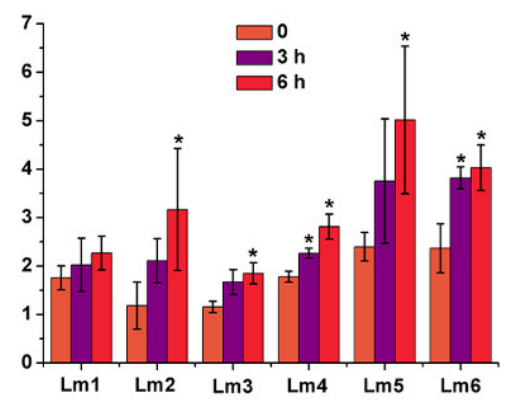

Figure 6. Evans blue staining analysis of roots of six ryegrass cultivars subjected to $\mathrm{Co}^{2+}(\mathbf{a}), \mathrm{Pb}^{2+}(\mathbf{b})$, or $\mathrm{Ni}^{2+}$ (c) stress for 3 and $6 \mathrm{~h}$. Roots of treated samples were washed with distilled water, and soaked in 0.025\% Evan's blue dye for 15 min. Stained samples were cleared with distilled water, and then observed and photographed under a BX41 light microscope. Significant differences were determined by $t$-test in Excel $2010(* * p<0.01, * 0.01<p<0.05)$.

\subsection{Comprehensive Evaluation of $\mathrm{Co}^{2+}, \mathrm{Pb}^{2+}$, and $\mathrm{Ni}^{2+}$ Tolerance of Six Ryegrass Cultivars}

Plants' tolerance to heavy metals is complex. Therefore, it is poorly represented using a single index of tolerance. In this study, the effects of different concentrations of $\mathrm{Co}^{2+}, \mathrm{Pb}^{2+}$, and $\mathrm{Ni}^{2+}$ on several morphological and physiological indexes of six ryegrass cultivars were studied, and tolerance was comprehensively evaluated using the membership function method [16,17]. The six cultivars were ranked, from most to least tolerant, as follows: to $\mathrm{Co}^{2+}, \mathrm{Lm} 1>\mathrm{Lm} 6>\operatorname{Lm} 4>\mathrm{Lm} 3>\mathrm{Lm} 5>\mathrm{Lm} 2$ (Table S2); to $\mathrm{Pb}^{2+}, \mathrm{Lm} 1>\mathrm{Lm} 5>\mathrm{Lm} 2>\mathrm{Lm} 6$ $>\mathrm{Lm} 4>\mathrm{Lm} 3$ (Table S3); and to $\mathrm{Ni}^{2+}, \mathrm{Lm} 1>\mathrm{Lm} 3>\mathrm{Lm} 4>\mathrm{Lm} 2>\mathrm{Lm} 5>\mathrm{Lm} 6$ (Table S4). Thus, compared with the other five cultivars, $\mathrm{Lm} 1$ showed stronger tolerance to $\mathrm{Co}^{2+}, \mathrm{Pb}^{2+}$, and $\mathrm{Ni}^{2+}$.

\subsection{Heavy Metal Accumulation in Shoots and Roots of Six Ryegrass Cultivars}

To understand the translocation and accumulation of $\mathrm{Co}^{2+}, \mathrm{Pb}^{2+}$, and $\mathrm{Ni}^{2+}$ in the six ryegrass cultivars, we conducted milestone microwave digester and ICP-MS analyses. In the $\mathrm{Co}^{2+}$ treatment, the $\mathrm{Co}^{2+}$ concentration in shoots was lower in $\mathrm{Lm} 1$ than in $\mathrm{Lm} 4$ and Lm6 $(p<0.05)$, but was not significantly different between Lm1 and the other three cultivars (Figure 7a). The $\mathrm{Pb}^{2+}$ and $\mathrm{Ni}^{2+}$ concentrations in shoots were significantly lower in Lm1 than in the other five ryegrass cultivars $(p<0.05$, Figure $7 \mathrm{~b}, \mathrm{c})$. These results showed that Lm1 translocated a small amount of heavy metals from roots to shoots under $\mathrm{Co}^{2+}$, $\mathrm{Pb}^{2+}$, and $\mathrm{Ni}^{2+}$ stresses. 

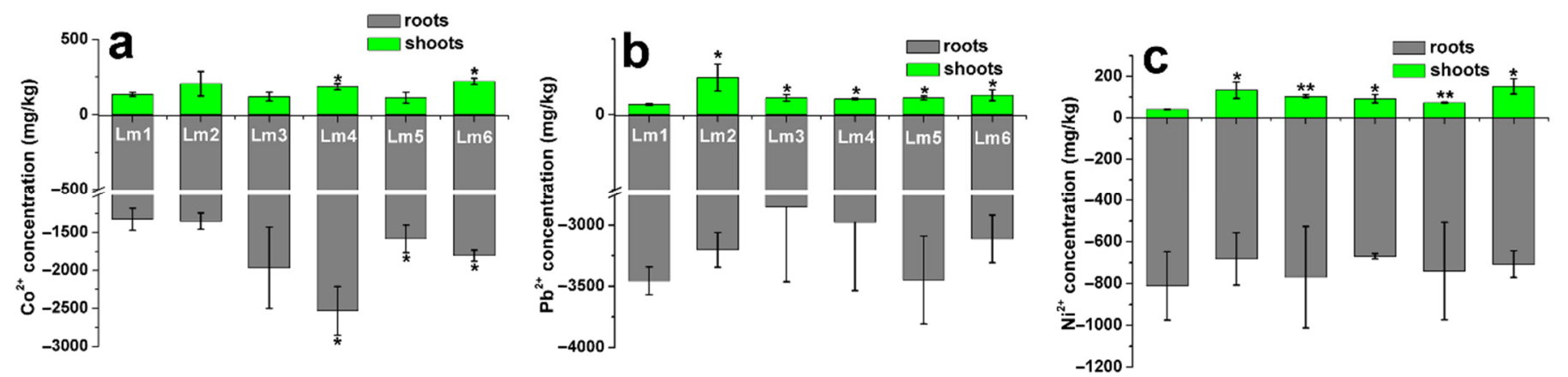

Figure 7. Concentrations of $\mathrm{Co}^{2+}, \mathrm{Pb}^{2+}$, and $\mathrm{Ni}^{2+}$ in shoots and roots of six ryegrass cultivars subjected to $\mathrm{Co}^{2+}, \mathrm{Pb}^{2+}$, or $\mathrm{Ni}^{2+}$ stress for $24 \mathrm{~h}$. Milestone microwave digester and ICP-MS was used to digest and detect heavy metals in shoots and roots. Data are mean \pm standard error from three independent experiments. Asterisks indicate significant differences from control levels $\left({ }^{* *} p<0.01,{ }^{*} 0.01<p<0.05\right.$ ). (a) $\mathrm{Co}^{2+}$ concentrations in shoots and roots of six ryegrass cultivars under $\mathrm{CoCl}_{2}$ treatment; (b) $\mathrm{Pb}^{2+}$ concentrations in shoots and roots of six ryegrass cultivars under $\mathrm{Pb}\left(\mathrm{NO}_{3}\right)_{2}$ treatment; (c) $\mathrm{Ni}^{2+}$ concentrations in shoots and roots of six ryegrass cultivars under $\mathrm{NiSO}_{4}$ treatment.

\subsection{Changes in Transcript Levels of Genes Encoding Heavy Metal Transporters in Response to Heavy Metal Treatments}

The comprehensive evaluation showed that, compared with the other five cultivars, Lm1 had better tolerance to $\mathrm{Co}^{2+}, \mathrm{Pb}^{2+}$, and $\mathrm{Ni}^{2+}$. To explore the mechanisms of its tolerance, we conducted RT-qPCR analyses to determine the transcript levels of 15 genes encoding heavy metal transporters in the shoots and roots of Lm1 plants treated with $\mathrm{Co}^{2+}, \mathrm{Pb}^{2+}$ and $\mathrm{Ni}^{2+}$. As shown in Figures 8 and 9 in the $500 \mathrm{mg} / \mathrm{L} \mathrm{Co}^{2+}$ treatment, the transcript levels of $A B C B 4, A B C G 37$, and $A B C G 48$ in Lm1 shoots increased from 24 to $48 \mathrm{~h}$ (Figure $8 \mathrm{a}, \mathrm{c}, \mathrm{d} ; p<0.05$ ), and those of CNR2 and HMA5 slightly increased (Figure 8f,m; $p<0.05)$. In contrast, the transcript levels of ABCB21, CNR1, CNR13, NRAMP1, NRAMP6, YSL6, YSL12, MTP1, CBP60, and MRP decreased (Figure 8b,e,g-l,n,o).

The transcript levels of $A B C B 4, A B C B 21$, ABCG37, CNR1, CNR2, CNR13, YSL6, YSL12, $C B P 60$, and MRP in Lm1 shoots were decreased at 24 and $48 \mathrm{~h}$ of the $1000 \mathrm{mg} / \mathrm{L} \mathrm{Pb}^{2+}$ treatment (Figure 8a-c,e,f,g,i-k,n,o), but those of ABCG48, NRAMP1, NRAMP6, MTP1, and HMA5 were increased, compared with their respective levels at $0 \mathrm{~h}$ (Figure $8 \mathrm{~d}, \mathrm{~h}, \mathrm{i}, \mathrm{l}, \mathrm{m}$; $p<0.05)$. In the shoots of Lm1, the transcript levels of $A B C B 4, A B C G 37, A B C G 48, C N R 1$, NRAMP6, MTP1, CBP60, and MRP increased in the $500 \mathrm{mg} / \mathrm{L} \mathrm{Ni}^{2+}$ treatment (Figure 8a,c-e,i,n,o; $p<0.05$ ), while those of ABCB21, CNR2, CNR13, NRAMP1, YSL6, YSL12, and HMA5 decreased (Figure $8 \mathrm{~b}, \mathrm{f}-\mathrm{h}, \mathrm{j}, \mathrm{k}, \mathrm{m}$ ).

The transcript levels of $A B C B 4, A B C G 37, A B C G 48, C N R 1, C N R 2, C N R 13, N R A M P 1$, NRAMP6, YSL6, YSL12, MTP1, HMA5 CBP60, and MRP in roots of Lm1 were markedly increased in the $500 \mathrm{mg} / \mathrm{L} \mathrm{Co}^{2+}$ treatment (Figure $9 \mathrm{c}-\mathrm{i}, \mathrm{k}-\mathrm{O} ; p<0.05$ ), while those of $A B C B 4$ and YSL6 were slightly higher than in the control (Figure 9a,j; $p<0.05$ ). In the roots, only $A B C B 21$ showed lower transcript levels in the $500 \mathrm{mg} / \mathrm{L} \mathrm{Co}^{2+}$ treatment than in the control (Figure 9b).

In the $1000 \mathrm{mg} / \mathrm{L} \mathrm{Pb}^{2+}$ and $500 \mathrm{mg} / \mathrm{L} \mathrm{Ni}^{2+}$ treatments, 11 genes were up-regulated in the roots, compared with their respective levels in the control (Figure $9 ; p<0.05$ ). 

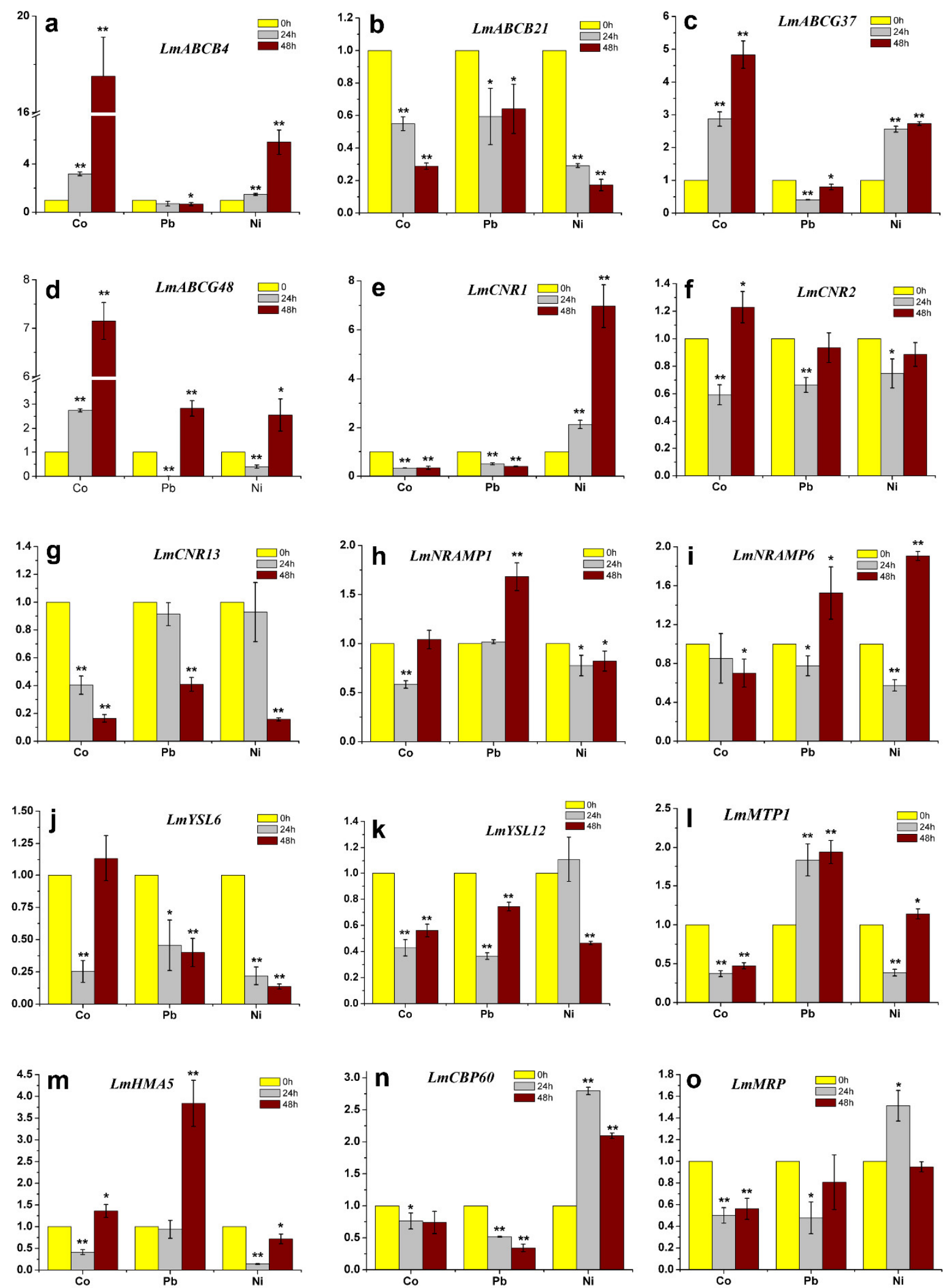

Figure 8. Relative transcript levels of 15 genes encoding transporters in $\mathrm{Lm} 1$ shoots. Gene transcript levels were determined by RT-qPCR at 24 and $48 \mathrm{~h}$ of $\mathrm{Co}^{2+}, \mathrm{Pb}^{2+}$, or $\mathrm{Ni}^{2+}$ treatment. (a) LmABCB4, (b) LmABCB21, (c) LmABCG37, (d) LmABCG48, (e) LmCNR1, (f) LmCNR2, (g) LmCNR13, (h) LmNRAMP1, (i) LmNRAMP6, (j) LmYSL6, (k) LmYSL12, (1) LmMTP1, (m) LmHMA5, (n) LmCBP60, (o) LmMRP. Data are means \pm SE of three independent samples. Data were analyzed by $t$-test, and significant differences are indicated by asterisk $\left({ }^{*} 0.01<p<0.05,{ }^{* *} p<0.01\right)$. 

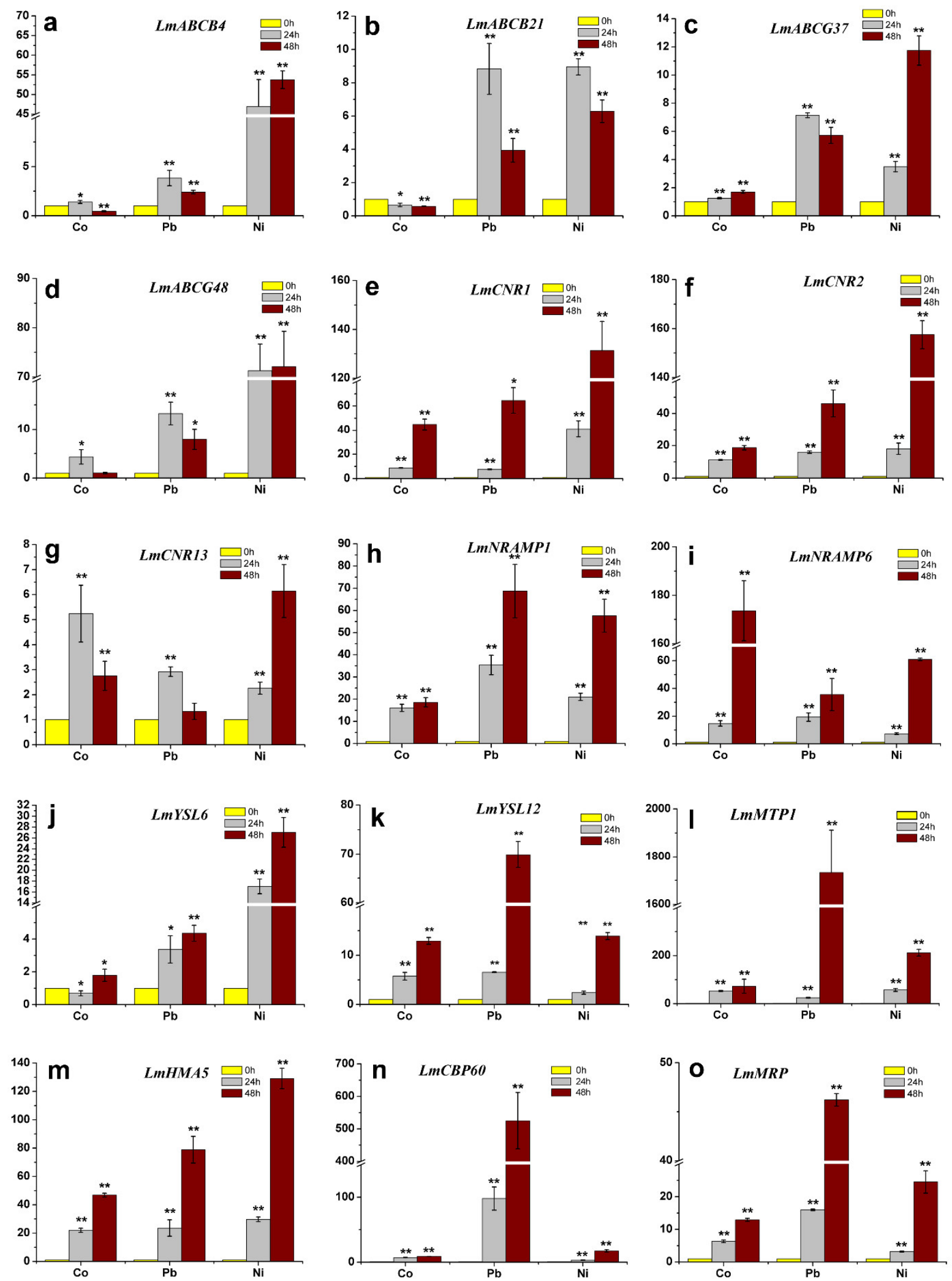

Figure 9. Relative transcript levels of 15 genes encoding transporters in $\mathrm{Lm} 1$ roots. Gene transcript levels were determined by RT-qPCR at 24 and $48 \mathrm{~h}$ of $\mathrm{Co}^{2+}, \mathrm{Pb}^{2+}$, or $\mathrm{Ni}^{2+}$ treatment. (a) LmABCB4, (b) LmABCB21, (c) LmABCG37, (d) LmABCG48, (e) LmCNR1, (f) LmCNR2, (g) LmCNR13, (h) LmNRAMP1, (i) LmNRAMP6, (j) LmYSL6, (k) LmYSL12, (1) LmMTP1, (m) LmHMA5, (n) LmCBP60, (o) LmMRP. Data are means \pm SE of three independent samples. Data were analyzed by $t$-test, and significant differences are indicated by asterisk $\left({ }^{*} 0.01<p<0.05,{ }^{* *} p<0.01\right)$. 


\section{Discussion}

\subsection{Effects of Heavy Metals on Seed Germination of Six Ryegrass Cultivars}

Seed germination is the first important stage of the plant life cycle, and the germination rate reflects seedling emergence. Seed germination is a prerequisite for plant survival under stress conditions. Previous studies have reported decreased rates of seed germination of alfalfa (Medicago sativa L.) and rice under Co stress [18], shepherd's purse and black bean under $\mathrm{Pb}$ stress [19,20], and millet and oat under Ni stress [7]. In the present study, the seed germination of six ryegrass cultivars was inhibited by high concentrations of $\mathrm{Co}^{2+}$, $\mathrm{Pb}^{2+}$, and $\mathrm{Ni}^{2+}$. However, the relative inhibition rate of germination of $\mathrm{Lm} 1$ was lower than those of the other five ryegrass cultivars under $\mathrm{Co}^{2+}, \mathrm{Pb}^{2+}$ and $\mathrm{Ni}^{2+}$ stresses (Figure 1). Thus, we concluded that $\mathrm{Lm} 1$ had better tolerance to $\mathrm{Co}, \mathrm{Pb}$, and Ni stresses, compared with the other five ryegrass cultivars.

\subsection{Effects of $\mathrm{Co}^{2+}, \mathrm{Pb}^{2+}$, and $\mathrm{Ni}^{2+}$ Stresses on Ryegrass Growth}

Plant height, root length, and biomass are the most basic growth indexes, and they are important criteria to evaluate the stress tolerance of plants and the degree of stress. Previous studies have shown that the accumulation of heavy metals affects plant growth and development, and that seedlings exposed to heavy metals become more sensitive to external environmental stimuli $[14,15]$. In another study, the shoot length and root length of rice seedlings tended to decrease as $\mathrm{Co}^{2+}$ stress became more severe [18]. In Chenopodium murale treated with 300,400 , and $500 \mathrm{mg} / \mathrm{kg} \mathrm{Pb}^{2+}$, the shoot length, root length, and biomass decreased with increasing $\mathrm{Pb}^{2+}$ concentrations [21]. In rice, the shoot length, root length, dry weight, and fresh weight of plants under $200 \mu \mathrm{M} \mathrm{Ni}^{2+}$ stress were $31.05 \%, 32.07 \%, 65.09 \%$, and $63.88 \%$ lower, respectively, than in the control, and $\mathrm{Ni}^{2+}$ stress had a stronger inhibitory effect on biomass than on plant height [22]. In the present study, the relative inhibition rates of shoot length and root length were lower in Lm1 than in the other cultivars under $\mathrm{Co}^{2+}, \mathrm{Pb}^{2+}$ and $\mathrm{Ni}^{2+}$ stresses, indicating that it was more tolerant to heavy metal stresses. We observed that all ryegrass cultivars showed inhibited growth in the heavy metal treatments, compared with the control, and that heavy metals had a stronger inhibitory effect on root length than on shoot length.

\subsection{Effects of $\mathrm{CO}^{2+}, \mathrm{Pb}^{2+}$, and $\mathrm{Ni}^{2+}$ Stresses on Total Antioxidant Capacity of Ryegrass}

Plants produce ROS under heavy metal stress. To maintain the balance of ROS in vivo, plants have evolved a complex antioxidant system to protect their cellular structure [23]. The activities of antioxidant enzymes (such as superoxide dismutase, SOD; catalase, CAT; and ascorbate peroxidase, APX) often increase under stress conditions. Superoxide dismutase decomposes ROS into $\mathrm{H}_{2} \mathrm{O}_{2}$, which is then removed by CAT and APX [23]. Studies on rice plants subjected to $100 \mu \mathrm{M} \mathrm{Pb}^{2+}$ stress showed that SOD, APX, and glutathione reductase activities increased, and the levels of antioxidant substances, such as ascorbic acid and glutathione decreased [24]. In Camelina sativa, the activities of SOD, CAT, and APX were up-regulated under $\mathrm{Ni}^{2+}$ treatment [25]. In contrast, in Brassica juncea subjected to a high $\mathrm{Cu}^{2+}$ treatment, SOD, CAT, and peroxidase activities decreased [19]. In this study, the total antioxidant capacity of six ryegrass cultivars was significantly increased by a $500 \mathrm{mg} / \mathrm{L} \mathrm{Co}^{2+}$ treatment, unaffected by a $500 \mathrm{mg} / \mathrm{L} \mathrm{Ni}^{2+}$ treatment, and significantly decreased by a $1000 \mathrm{mg} / \mathrm{L} \mathrm{Pb}^{2+}$ treatment. The very high concentration of $\mathrm{Pb}^{2+}$ may have damaged plant cells or down-regulated other non-enzymatic antioxidants (such as ascorbic acid), leading to decreased total antioxidant capacity [26].

\subsection{Accumulation and Translocation of Heavy Metals in Ryegrass Plants}

The $\mathrm{Co}^{2+}, \mathrm{Pb}^{2+}$, and $\mathrm{Ni}^{2+}$ concentrations in shoots were generally lower in $\mathrm{Lm} 1$ than in the other ryegrass cultivars, indicating that $\mathrm{Lm} 1$ accumulated less heavy metals than did the other cultivars. Because it accumulated fewer heavy metals, it was able to tolerate higher concentrations of $\mathrm{Co}^{2+}, \mathrm{Pb}^{2+}, \mathrm{Ni}^{2+}$. This explains why $\mathrm{Lm} 1$ showed stronger tolerance than that of other ryegrass cultivars to heavy metals. 
Plants have different types of transporters that help to translocate heavy metal ions and maintain the ion balance in the cytoplasm. We detected increased transcript levels of some genes encoding transporters in $\mathrm{Lm} 1$ treated with $\mathrm{Co}^{2+}, \mathrm{Pb}^{2+}$, or $\mathrm{Ni}^{2+}$. A superfamily of ATP-binding cassette (ABC) transporters (including ABCA-ABCH types) is involved in heavy metal transport. For example, in hybrid poplar, PcABCG36 localized on the plasma membrane transports $\mathrm{Pb}^{2+}$ from the cytoplasm across the plasma membrane [27]. In rice, OsABCG36 inhibits Cd accumulation in root cells and enhances $\mathrm{Cd}$ tolerance [28]. In Arabidopsis, AtABCG37 is located in the plasma membrane of root cells, and it regulates auxin translocation [29]. A previous study reported that $L m A B C G 37$ in ryegrass roots was up-regulated by $\mathrm{Cd}$ treatment [15], and also by treatments with $\mathrm{Co}, \mathrm{Pb}$, or $\mathrm{Ni}$, suggesting that it is involved in the translocation of heavy metal ions in roots. In Arabidopsis, AtABCB21 is located in the plasma membrane of root pericycle cells, where it imports or exports auxin, whereas AtABCB4 is responsible for exporting auxin [30]. In the present study, $L m A B C B 21$ was down-regulated in $\mathrm{Lm} 1$ shoots under $\mathrm{Co}^{2+}, \mathrm{Pb}^{2+}$ and $\mathrm{Ni}^{2+}$ stresses, indicating that LmABCB21 might not be involved in heavy metal accumulation and/or transport from roots to shoots. In contrast, $L m A B C G 48$ was up-regulated in shoots and roots of Lm1 plants treated with $\mathrm{Co}^{2+}, \mathrm{Pb}^{2+}$, or $\mathrm{Ni}^{2+}$. Therefore, LmABCG48 might be involved in the efflux of excess heavy metals from the plasma membrane. In addition, LmABCG4 and LmABCG37 had higher expression at $\mathrm{Co}^{2+}$ and $\mathrm{Ni}^{2+}$ treatments in $\mathrm{Lm} 1$ shoots and roots, implying that they both were involved with $\mathrm{Co}^{2+}$ and $\mathrm{Ni}^{2+}$ translocation from roots to shoots.

A previous study found that the rice OsHMA5 mutant accumulated lower levels of copper ions in the xylem sap, suggesting that OsHMA5 may mediate the translocation of heavy metals from the roots to the shoots through the vascular bundle [31,32]. A homolog of HMA5 in poplar, PtHMA4, was also found to be localized at the plasma membrane. Its encoding gene, PtHMA4, was up-regulated in the roots of plants treated with $\mathrm{Co}$ or $\mathrm{Pb}$, suggesting that it may be involved in the transport of $\mathrm{Co}$ and $\mathrm{Pb}$ from roots to shoots [33]. We detected increased transcript levels of LmHMA5 in shoots and roots of Lm1 treated with $\mathrm{Pb}$, suggesting that LmHMA5 might be involved in the translocation of $\mathrm{Pb}^{2+}$ from the roots to the shoots.

The NRAMP proteins are membrane-located transporters of heavy metals including $\mathrm{Co}^{2+}, \mathrm{Pb}^{2+}$, and $\mathrm{Ni}^{2+}$. In Chlamydomonas, CrNRAMP1 is localized at the plasma membrane, and the CrNRAMP1 mutant showed increased Co tolerance [34]. In poplar, PtNARMP1.3 located in the plasma membrane transports $\mathrm{Pb}^{2+}$ from outside the cells to the cytoplasm for chelation [35]. In Thlaspi japonicum, TjNARMP4 is located on the vacuolar membrane, and is involved in $\mathrm{Ni}^{2+}$ accumulation and translocation. Overexpression of TjNARMP4 increased the contents of $\mathrm{Ni}$ in cells and enhanced sensitivity to $\mathrm{Ni}^{2+}$ [36]. Two homologs of NARMP4 in potato, StNRAMP2 and StNRAMP3, were found to be significantly up-regulated in roots by a $\mathrm{Ni}^{2+}$ treatment, and were found to be involved in the absorption and translocation of $\mathrm{Ni}^{2+}$ [37]. In the present study, in Lm1 treated with heavy metals, the transcript levels of $L m N R A M P 1$ and $L m N R A M P 6$ were slightly increased in the shoots, but strongly increased in the roots. These results suggest that the proteins encoded by LmNRAMP1 and $L m N R A M P 6$ participate in translocation of $\mathrm{Co}^{2+}, \mathrm{Pb}^{2+}$, and $\mathrm{Ni}^{2+}$, analogous to the roles of StNRAMP2 and StNRAMP3 in potato.

Metal tolerance proteins in the cation diffusion facilitator family are responsible for transporting heavy metal ions such as $\mathrm{Co}^{2+}, \mathrm{Ni}^{2+}$, and $\mathrm{Cd}^{2+}$. In Thlaspi goesingense, TgMTP1 is localized at the vacuolar membrane in shoots and roots, and it transports $\mathrm{Ni}^{2+}$ into the vacuole for chelation [38]. In wheat, TuMTP1 located on the vacuolar membrane transports excess $\mathrm{Co}^{2+}$ into vacuoles [39]. In the present study, the LmMTP1 transcript levels were significantly higher in roots than in shoots. The probable role of its encoded protein is to transport $\mathrm{Co}^{2+}, \mathrm{Pb}^{2+}$, and $\mathrm{Ni}^{2+}$ into the vacuole of root cells for sequestration, because even small amounts of heavy metals can damage the shoots.

The YSL protein is mainly involved in $\mathrm{Fe}^{2+}$ and $\mathrm{Mn}^{2+}$ transport in cells, and is also related to $\mathrm{Pb}^{2+}$ and $\mathrm{Ni}^{2+}$ transport. In Arabidopsis, AtYSL4 is located on the vacuolar membrane and is responsible for transporting excess $\mathrm{Ni}^{2+}$ from cells out of vacuoles to 
relieve heavy metal toxicity [40]. The expression of YSL7 in roots of Brassica juncea was found to be up-regulated under high $\mathrm{Pb}$ stress. Similarly, under Ni treatment, the transcript level of BjYSL7 in the stem was found to be significantly increased. The overexpression of BjYSL7 in tobacco significantly increased the Ni content in shoots, providing evidence that YSL7 is involved in transporting Ni from roots to shoots [41]. In Lm1, LmYSL6 and LmYSL12 transcript levels were higher in roots than in shoots, but they decreased under $\mathrm{Co}, \mathrm{Pb}$, and $\mathrm{Ni}$ treatments. Thus, some YSL proteins might be involved in heavy metal uptake into the roots, but not in their translocation to shoots.

The cell number regulator (CNR) proteins belong to the placenta-specific 8 family, and their role is to regulate cell number and fruit size. However, TaCNR2, TaCNR5, and TuCNR10 are involved in the accumulation and translocation of $\mathrm{Cd}^{2+}, \mathrm{Zn}^{2+}$, and $\mathrm{Mn}^{2+}$ in the roots of wheat $[42,43]$. In this study, we detected higher transcript levels of LmCNR1, LmCNR2, and LmCNR13 in the roots of Lm1 treated with heavy metals, but they were down-regulated in shoots, implying that they do not participate in $\mathrm{Co}^{2+}, \mathrm{Pb}^{2+}$, and $\mathrm{Ni}^{2+}$ translocation.

CBP60 can participate in regulating salicylic acid biosynthesis, and CBP60 in transgenic Arabidopsis is sensitive to abscisic acid and enhances the tolerance to drought stress [44]. Because NtCBP4 can reduce $\mathrm{Ni}^{2+}$ concentration and enhance $\mathrm{Pb}^{2+}$ accumulation, respectively. Therefore, tobacco $\mathrm{NtCBP} 4$ presents improved $\mathrm{Ni}^{2+}$ tolerance and $\mathrm{Pb}^{2+}$ sensitivity [45]. $\mathrm{LmCBP} 60$ transcript levels in roots were significantly induced at $\mathrm{Co}^{2+}, \mathrm{Pb}^{2+}$, and $\mathrm{Ni}^{2+}$, and the expression level had 500 times than in the control under $\mathrm{Pb}^{2+}$ treatment.

MRP belongs to $A B C$ transporter sequence of $C$ subfamily, which may be associated with the translocation of $\mathrm{Cd}$ chelates or glutaminesynthease-Cd complexes in the vacuolar membrane. In addition, transcriptional levels of four MRPs are increased in treated roots from Arabidopsis [46]. AtMRP3 transporter and its promoter increased their expression in treated with $\mathrm{Cd}, \mathrm{Ni}, \mathrm{Co}, \mathrm{Pb}$, and As in transgenic Arabidopsis and Nicotiana [47]. Moreover, LmMRP, such as AtMRP3, also had higher expression at $\mathrm{Co}^{2+}, \mathrm{Pb}^{2+}$, and $\mathrm{Ni}^{2+}$ in ryegrass roots.

In summary, the main findings in this study were that we screened out a ryegrass cultivar ( $\mathrm{Lm} 1$ ) with strong tolerance to $\mathrm{Co}, \mathrm{Pb}$, and $\mathrm{Ni}$ through physiological and phenotypic analysis. However, the transcript levels of most genes (LmABCB4, LmABCG37, LmABCG48, LmCNR1, LmCNR2, LmCNR13, LmNARMP1, LmNARMP6, LmYSL6, LmYSL12, LmMTP1, LmHMA5, LmCBP60, and LmMRP) encoding heavy metal transporters were significantly higher in the heavy metal treatments than in the control in the roots. Moreover, in the shoots, only LmABCB4 and LmABCG37 were up-regulated in the $\mathrm{Co}$ and Ni treatments, and only LmABCG48 was up-regulated in all the heavy metal treatments (Figures 8 and 9). These indicated that LmABCB4, LmABCG37, and LmABCG48 are key component of the response to heavy metal accumulation and translocation. Further research is required to explore their role in more detail. Most transporters are not expressed in the shoots of Lm1, then heavy metals may not be transported to the shoots through the xylem. This may explain why Lm1 showed higher tolerance to heavy metals, compared with the other five cultivars. A recent study found that intercropping of ryegrass and Indian mustard can improve phytoremediation of antibiotics [48]. The inspiration for us is to use ryegrass intercropping with other herbaceous plants to enhance stress resistance and reduce the content of heavy metals in soil.

\section{Materials and Methods}

\subsection{Plant Materials and Tolerance Analysis}

The seeds of six ryegrass cultivars (designated as Lm1, Lm2, Lm3, Lm4, Lm5, and Lm6) were purchased from grass industry groups (Table S1). The seeds were disinfested with $0.5 \% v / v \mathrm{NaClO}_{3}$ for $15 \mathrm{~min}$, washed five to six times with sterile distilled water, and then dried with filter paper. The disinfested seeds were placed evenly in Petri dishes containing a double layer of filter paper, and $7 \mathrm{~mL}$ treatment solution $\left(\mathrm{CoCl}_{2}: 0,200\right.$, 500, 800, 1000, 2000 mg/L; $\mathrm{Pb}\left(\mathrm{NO}_{3}\right)_{2}:$ 0, 500, 1000, 1500, 2000, $3500 \mathrm{mg} / \mathrm{L} ; \mathrm{NiSO}_{4}:$ 0, 100, 
200, 500, 1000, $1500 \mathrm{mg} / \mathrm{L}$ ) was added to each dish. Each treatment had four replicates with 25 seeds per group (100 seeds/treatment). During the experiment, the cultivation conditions were as follows: $12 \mathrm{~h}$ light $/ 12 \mathrm{~h}$ dark photoperiod, $22^{\circ} \mathrm{C}$, and relative humidity of $60 \%$. The treatment solution was added to each Petri dish each day, and the number of germinated seeds was recorded every day for 5 days. On day 6 , the resulting seedings were put onto the 1/2 Murashige and Skoog solid media (Qingdao Hope Bio-technology Co. Ltd., Qingdao, China) and photographed. The shoot length and root length were detected by a vernier calipers.

\subsection{Determination of Total Antioxidant Capacity}

We used 14-day-old hydroponically grown seedlings in these experiments. Six cultivars of seedlings with similar growth were treated with $500 \mathrm{mg} / \mathrm{L} \mathrm{CoCl}_{2}, 1000 \mathrm{mg} / \mathrm{L}$ $\mathrm{Pb}\left(\mathrm{NO}_{3}\right)_{2}$, or $500 \mathrm{mg} / \mathrm{L} \mathrm{NiSO}_{4}$ for $0 \mathrm{~h}, 24 \mathrm{~h}$, and $48 \mathrm{~h}$. The same heavy metal concentrations were used in the further experiments. Then, the total antioxidant capacity of ryegrass cultivars was performed using an extraction kit (Solarbio, Beijing, China). $0.1 \mathrm{~g}$ fresh treated ryegrass samples (the whole seedling) were collected and ground on ice with $1.0 \mathrm{~mL}$ pre-cooled extraction buffer in with a pestle and mortar. The mixture was then centrifuged at $10000 \mathrm{rpm} / \mathrm{min}$ at $4{ }^{\circ} \mathrm{C}$ for $5 \mathrm{~min}$, and the supernatant was used for antioxidant assays. The absorbance was detected at $593 \mathrm{~nm}$ using UV-Vis spectrophotometer (Lambda 850, Storrs, CT, USA), and the total antioxidant capacity was calculated using standard curves.

\subsection{Evans Blue Staining Analyses}

We used 14-day-old hydroponically grown seedlings in these experiments. Six cultivars of seedlings with similar growth were treated for $0 \mathrm{~h}, 24 \mathrm{~h}$, and $48 \mathrm{~h}$. The roots of treated samples were washed with distilled water, and soaked in $0.025 \% w / v$ Evan's blue dye for $15 \mathrm{~min}$. The surface of stained samples was rinsed three times with distilled water, and then observed and photographed under a BX41 light microscope equipped with an Olympus DP80 CCD camera (Olympus, Tokyo, Japan). The roots of the six ryegrass cultivars were cut and weighed, then placed in a $10-\mathrm{mL}$ centrifuge tube. Then, $3 \mathrm{~mL} 1 \% \mathrm{w} / \mathrm{v}$ sodium dodecyl sulfate aqueous solution was added, and the mixture was left for 3 days to allow extraction of the dye. The absorbance value of the extract at $\mathrm{OD}_{600}$ was measured using a SpectraMax Absorbance Reader (Molecular Devices, Sunnyvale, CA, USA).

\subsection{Determination of Heavy Metal Concentrations in Seedlings' Shoots and Roots}

To explore the accumulation and translocation of $\mathrm{Co}^{2+}, \mathrm{Pb}^{2+}$, and $\mathrm{Ni}^{2+}$ in the shoots and roots of the six ryegrass cultivars, the heavy metal concentrations in tissues were determined by ICP-MS. After treatment for $24 \mathrm{~h}$, ryegrass plants were soaked in $10 \mathrm{mM}$ EDTA for $30 \mathrm{~min}$ to remove residual metals from the surface. The seedlings were separated into shoots and roots, and each part was dried at $80^{\circ} \mathrm{C}$ for 3 days. The dried samples were weighed and then digested in $6 \mathrm{~mL} \mathrm{HNO}_{3}$ (Aladdin, Shanghai, China) for $2 \mathrm{~h}$, and then digested with a Milestone microwave digester (Socisole, Italy). The microwave heating procedure was as follows: increase to $120^{\circ} \mathrm{C}$ at $5{ }^{\circ} \mathrm{C} / \mathrm{min}$, hold for $5 \mathrm{~min}$, increase to $150{ }^{\circ} \mathrm{C}$ at $5^{\circ} \mathrm{C} / \mathrm{min}$, hold for $10 \mathrm{~min}$, increase to $190^{\circ} \mathrm{C}$ at $5^{\circ} \mathrm{C} / \mathrm{min}$, hold for $20 \mathrm{~min}$. The mixture was cooled, the inner cover of the digestion tube was rinsed with a small amount of water, and then the microwave digestion tube was placed in a temperature-controlled porous acid extractor. The volume of the acid was reduced to the size of a bean at $160{ }^{\circ} \mathrm{C}$, and then adjusted to $25 \mathrm{~mL}$ with pure water [42]. A series of standard solutions were prepared and tested, and $5 \% \mathrm{HNO}_{3}$ was as blank control. The absorption tube was inserted into the solution after digestion. We selected the elements $(\mathrm{Co}, \mathrm{Pb}$, and $\mathrm{Ni})$ to be analyzed. The $\mathrm{Co}, \mathrm{Pb}$, and $\mathrm{Ni}$ concentrations were detected by ICP-MS using a PerkinElmer instrument (PerkinElmer, Shelton, CT, USA). 


\subsection{Gene Expression Analyses in Lm1}

We used 14-day-old hydroponically grown seedlings of Lm1 in this experiment. The seedlings were treated for $0 \mathrm{~h}, 24 \mathrm{~h}$, and $48 \mathrm{~h}$, and shoots and roots were collected for gene transcript analyses. Total RNA was extracted with Trizol reagent (Invitrogen, Carlsbad, CA, USA). The HiScript ${ }^{\circledR}$ III 1 st Strand cDNA Synthesis Kit (Vazyme, Biotech Co., Ltd., Nanjing, China) was used to transcribe RNA into cDNA. The transcript levels of the following genes encoding heavy metal transporters were determined: ATP-binding cassette (ABC) B-type transporter 4 (ABCB4), ABCB21, ABC G-type transporter 37 (ABCG37), ABCG48, cell number regulator 1 (CNR1), CNR2, CNR13, natural resistance associated macrophage protein 4 (NRAMP4), NRAMP6, Yellow stripe-like 6 (YSL6), YSL12, metal tolerance protein 1 (MTP1), heavy metal ATPase 5 (HMA5), calmodulin-binding protein 60 (CBP60), and multidrug resistanceassociated protein $(M R P)$. The actin and gene-specific primers were provided in Table S5. The real-time PCR analyses were performed containing Hieff ${ }^{\mathrm{TM}}$ qPCR SYBR Green Master Mix (YEASEN, Shanghai, China), and conducted using the CFX96 Touch Real-Time PCR assay system (Bio-Rad, Hercules, CA, USA). The relative gene transcript levels were calculated using the $2^{-\Delta \Delta C T}$ method [49].

\subsection{Statistical Analysis}

Data shown in figures and tables are means \pm standard error from three independent biological replicates. Mean values were compared among groups using $t$-test and one-way ANOVA, and the significance of difference was considered at $p<0.05$. Statistical analyses were conducted using Excel 2010 and SPSS 13.0 software. Figures were constructed using Origin 8 software.

Supplementary Materials: The following are available online at https:/ /www.mdpi.com/article/ $10.3390 /$ ijms222413583/s1.

Author Contributions: S.G., K.Q. and J.W.: designed the research; S.Q., Y.T. and Q.S.: conducted the experiments. T.C. and K.Q.: analyzed the data; K.Q.: wrote the manuscript. All authors have read and agreed to the published version of the manuscript.

Funding: This study was supported by the National Natural Science Foundation of China (Grant No. 31800200 and 31972450), the Natural Science Foundation of Heilongjiang Province of China (Grant No. YQ2020C002), the Postdoctoral Research Initiation Funding Project of Heilongjiang Province (Grant No. LBH-Q19084).

Institutional Review Board Statement: Not applicable.

Informed Consent Statement: Not applicable.

Data Availability Statement: Not applicable.

Conflicts of Interest: The authors declare no conflict of interest.

\section{References}

1. Yang, Q.Q.; Li, Z.Y.; Lu, X.N.; Duan, Q.N.; Huang, L.; Bi, J. A review of soil heavy metal pollution from industrial and agricultural regions in China: Pollution and risk assessment. Sci. Total Environ. 2018, 642, 690-700. [CrossRef]

2. Chonokhuu, S.; Batbold, C.; Chuluunpurev, B.; Battsengel, E.; Dorjsuren, B.; Byambaa, B. Contamination and health risk assessment of heavy metals in the soil of major cities in Mongolia. Int. J. Environ. Res. Public Health 2019, 16, 2552. [CrossRef] [PubMed]

3. Ai, S.W.; Liu, B.L.; Yang, Y.; Ding, J.; Yang, W.Z.; Bai, X.J.; Naeem, S.; Zhang, Y.M. Temporal variations and spatial distributions of heavy metals in a waste water-irrigated soil-eggplant system and associated influencing factors. Ecotoxicol. Environ. Saf. 2018, 158, 204-214. [CrossRef]

4. Liu, G.N.; Tao, L.; Liu, X.H.; Hou, J.; Wang, A.J.; Li, R.P. Heavy metal speciation and pollution of agricultural soils along Jishui River in non-ferrous metal mine area in Jiangxi Province. China J. Geochem. Explor. 2013, 132, 156-163. [CrossRef]

5. Xue, H.Q.; Zhao, L.; Liu, X.D. Characteristics of heavy metal pollution in road runoff in the Nanjing urban area, East China. Water Sci. Technol. 2020, 81, 1961-1971. [CrossRef]

6. Kosiorek, M.; Wyszkowski, M. Effect of cobalt on environment and living organisms-A review. Appl. Ecol. Environ. Res. 2019, 17, 11419-11449. [CrossRef] 
7. Gupta, V.; Jatav, P.K.; Verma, R.; Kothari, S.L.; Kachhwaha, S. Nickel accumulation and its effect on growth, physiological and biochemical parameters in millets and oats. Environ. Sci. Pollut. Res. 2017, 24, 23915-23925. [CrossRef]

8. Shahzad, B.; Tanveer, M.; Rehman, A.; Cheema, S.A.; Fahad, S.; Rehman, S.; Sharma, A. Nickel: Whether toxic or essential for plants and environment-A review. Plant Physiol. Biochem. 2018, 132, 641-651. [CrossRef]

9. Fiala, R.; Repka, V.; Ciamporova, M.; Martinka, M.; Pavlovkin, J. The effect of cadmium-nickel interactions on superoxide production, cell viability and membrane potential (EM) in roots of two maize cultivars. Acta Biol. Hung. 2015, 66, 192-204. [CrossRef] [PubMed]

10. Yilmaz, D.D.; Parlak, K.U. Nickel-induced changes in lipid peroxidation, antioxidative enzymes, and metal accumulation in Lemna gibba. Int. J. Phytoremediat. 2011, 13, 805-817. [CrossRef] [PubMed]

11. Gruenhage, L.; Jaeger, H.J. Effect of heavy metals on growth and heavy metal content of Allium porrum L. and Pisum sativum L. J. Appl. Bot. Angew. Bot. 1985, 59, 11-27.

12. Kumar, A.; Prasad, M. Plant-lead interactions: Transport, toxicity, tolerance, and detoxification mechanisms. Ecotoxicol. Environ. Saf. 2018, 166, 401-418. [CrossRef]

13. Illi, J.C.; Vancetta, T.; Alves, D.D.; Osorio, D.M.M.; Bianchin, L.; de Quevedo, D.M.; Juchem, F. Integrated assessment of air pollution by metals and source apportionment using ryegrass (Lolium multiflorum Lam.) in southern Brazil. Environ. Sci. Pollut. Res. 2017, 24, 2790-2803. [CrossRef] [PubMed]

14. Liu, Z.L.; He, X.Y.; Chen, W.; Zhao, M.Z. Ecotoxicological responses of three ornamental herb species to cadmium. Environ. Toxicol. Chem. 2013, 32, 1746-1751. [CrossRef]

15. Wang, J.G.; Zhao, J.C.; Feng, S.; Zhang, J.Z.; Gong, S.F.; Qiao, K.; Zhou, A.M. Comparison of cadmium uptake and transcriptional responses in roots reveal key transcripts from high and low-cadmium tolerance ryegrass cultivars. Ecotoxicol. Environ. Saf. 2020, 203, 110961. [CrossRef] [PubMed]

16. Jin, D.S.; Xu, Y.C.; Gui, H.P.; Zhang, H.H.; Dong, Q.; Sikder, R.K.; Wang, X.R.; Yang, G.Z.; Song, M.Z. Evaluation of cotton (Gossypium hirsutum L.) leaf abscission sensitivity triggered by thidiazuron through membership function value. Plants 2021, 10, 49. [CrossRef] [PubMed]

17. Yan, C.J.; Song, S.H.; Wang, W.B.; Wang, C.L.; Li, H.B.; Wang, F.; Li, S.Y.; Sun, X.G. Screening diverse soybean genotypes for drought tolerance by membership function value based on multiple traits and drought tolerant coefficient of yield. BMC Plant Biol. 2020, 20, 321. [CrossRef]

18. Zhang, H.; Kou, J.T.; Shi, S.L. Physiological and biochemical responses of Medicago sativa seed to cobalt stress. Acta Pratacul. Sin. 2015, 24, 146-153.

19. Mathad, P.; Pratima, H. Copper toxicity causes oxidative stress in Brassica juncea L. seedings. Indian J. Plant Physiol. 2009, 14, 397-401.

20. Kumar, M.; Jayaraman, P. Toxic Effect of Lead Nitrate $\left[\mathrm{Pb}\left(\mathrm{NO}_{3}\right)_{2}\right]$ on the Black Gram Seedlings (Vigna mungo (L.) Hepper). Int. J. Adv. Res. Biol. Sci. 2014, 1, 209-213.

21. Sidhu, G.P.S.; Bali, A.S.; Bhardwaj, R.; Singh, H.P.; Batish, D.R.; Kohli, R.K. Bioaccumulation and physiological responses to lead $(\mathrm{Pb})$ in Chenopodium murale L. Ecotoxicol. Environ. Saf. 2018, 151, 83-90. [CrossRef] [PubMed]

22. Rizwan, M.; Imtiaz, M.; Dai, Z.H.; Mehmood, S.; Adeel, M.; Liu, J.C.; Tu, S.X. Nickel stressed responses of rice in Ni subcellular distribution, antioxidant production, and osmolyte accumulation. Environ. Sci. Pollut. Res. 2017, 24, 20587-20598. [CrossRef] [PubMed]

23. Gill, S.S.; Tuteja, N. Reactive oxygen species and antioxidant machinery in abiotic stress tolerance in crop plants. Plant Physiol. Biochem. 2010, 48, 909-930. [CrossRef]

24. Chen, Q.; Zhang, X.Y.; Liu, Y.Y.; Wei, J.Y.; Shen, W.B.; Shen, Z.G.; Cui, J. Hemin-mediated alleviation of zinc, lead and chromium toxicity is associated with elevated photosynthesis, antioxidative capacity; suppressed metal uptake and oxidative stress in rice seedlings. Plant Growth Regul. 2017, 81, 253-264. [CrossRef]

25. Duman, F.; Ozturk, F. Nickel accumulation and its effect on biomass, protein content and antioxidative enzymes in roots and leaves of watercress. J. Environ. Sci. 2010, 22, 526-532. [CrossRef]

26. Georgiadou, E.C.; Ewa, K.; Katarzyna, P.; Katarzyna, P.; Kamila, K.; Beata, S.; Joanna, L.; Vasileios, F. Influence of heavy metals $(\mathrm{Ni}, \mathrm{Cu}$, and $\mathrm{Zn}$ ) on nitro-oxidative stress responses, proteome regulation and allergen production in basil (Ocimum basilicum $\mathrm{L}$.) plants. Front. Plant Sci. 2018, 9, 862. [CrossRef]

27. Abolghassem, E.; Ding, Y.; Mokhberdoran, F.; Xie, Y.F. Heavy metal stress and some mechanisms of plant defense response. Sci. World J. 2015, 2015, 756120.

28. Fu, S.; Lu, Y.S.; Zhang, X.; Yang, G.Z.; Chao, D.; Wang, Z.G.; Shi, M.X.; Chen, J.G.; Chao, D.Y.; Li, R.B.; et al. The ABC transporter ABCG36 is required for cadmium tolerance in rice. J. Exp. Bot. 2019, 70, 5909-5918. [CrossRef]

29. Ruzicka, K.; Strader, L.C.; Bailly, A.; Yang, H.B.; Blakeslee, J.; Langowski, L.; Nejedla, E.; Fujita, H.; Itoh, H.; Syono, K.; et al. Arabidopsis PIS1 encodes the ABCG37 transporter of auxinic compounds including the auxin precursor indole-3-butyric acid. Proc. Natl. Acad. Sci. USA 2010, 107, 10749-10753. [CrossRef] [PubMed]

30. Kamimoto, Y.; Terasaka, K.; Hamamoto, M.; Takanashi, K.; Fukuda, S.; Shitan, N.; Sugiyama, A.; Suzuki, H.; Shibata, D.; Wang, B.; et al. Arabidopsis ABCB21 is a facultative auxin importer/exporter regulated by cytoplasmic auxin concentration. Plant Cell Physiol. 2012, 53, 2090-2100. [CrossRef] 
31. Deng, F.L.; Yamaji, N.; Xia, J.X.; Ma, J.F. A member of the heavy metal P-type ATPase OsHMA5 is involved in xylem loading of copper in rice. Plant Physiol. 2013, 163, 1353-1362. [CrossRef] [PubMed]

32. Lin, Y.F.; Aarts, M.G.M. The molecular mechanism of zinc and cadmium stress response in plants. Cell. Mol. Life Sci. 2012, 69, 3187-3206. [CrossRef] [PubMed]

33. Li, D.D.; Xu, X.M.; Hu, X.Q.; Liu, Q.G.; Wang, Z.C.; Zhang, H.Z.; Wang, H.; Wei, M.; Wang, H.Z.; Liu, H.M.; et al. Genome-wide analysis and heavy metal-induced expression profiling of the HMA gene family in Populus trichocarpa. Front. Plant Sci. 2015, 6, 1149. [CrossRef]

34. Chang, P.; Yin, H.; Imanaka, T.; Igarashi, Y.; Li, N.N.; Luo, F. The metal transporter CrNRAMP1 is involved in zinc and cobalt transports in Chlamydomonas reinhardtii. Biochem. Biophys. Res. Commun. 2020, 523, 880-886. [CrossRef]

35. Shi, W.; Zhou, J.; Li, J.; Ma, C.F.; Zhang, Y.H.; Deng, S.R.; Yu, W. Lead exposure-induced defense responses result in low lead translocation from the roots to aerial tissues of two contrasting poplar species. Environ. Pollut. 2020, 271, 116346. [CrossRef] [PubMed]

36. Mizuno, T.; Usui, K.; Horie, K.; Nosaka, S.; Mizuno, N.; Obata, H. Cloning of three ZIP/Nramp transporter genes from a Ni hyperaccumulator plant Thlaspi japonicum and their $\mathrm{Ni}^{2+}$-transport abilities. Plant Physiol. Biochem. 2005, 43, 793-801. [CrossRef]

37. Tian, E.J.; He, G.D.; Qin, L.J.; Li, D.D.; Meng, L.L.; Huang, Y.; He, T.B. Genome-wide analysis of the NRAMP gene family in potato (Solanum tuberosum): Identification, expression analysis and response to five heavy metals stress. Ecotoxicol. Environ. Saf. 2021, 208, 111661. [CrossRef]

38. Montanini, B.; Blaudez, D.; Jeandroz, S.; Sanders, D.; Chalot, M. Phylogenetic and functional analysis of the Cation Diffusion Facilitator (CDF) family: Improved signature and prediction of substrate specificity. BMC Genom. 2007, 8, 107. [CrossRef] [PubMed]

39. Wang, F.H.; Qiao, K.; Liang, S.; Tian, S.Q.; Tian, Y.B.; Wang, H.; Chai, T.Y. Triticum urartu MTP1: Its ability to maintain Zn ${ }^{2+}$ and $\mathrm{Co}^{2+}$ homeostasis and metal selectivity determinants. Plant Cell Rep. 2018, 37, 1653-1666. [CrossRef]

40. Jaquinod, M.; Villiers, F.; Kieffer-Jaquinod, S.; Hugouvieu, V.; Bruley, C.; Garin, J.; Bourguignon, J. A proteomics dissection of Arabidopsis thaliana vacuoles isolated from cell culture. Mol. Cell. Proteom. 2007, 6, 394-412. [CrossRef]

41. Wang, J.W.; Li, Y.; Zhang, Y.X.; Chai, T.Y. Molecular cloning and characterization of a Brassica juncea yellow stripe-like gene, BjYSL7, whose overexpression increases heavy metal tolerance of tobacco. Plant Cell Rep. 2013, 32, 651-662. [CrossRef] [PubMed]

42. Qiao, K.; Tian, Y.B.; Hu, Z.L.; Chai, T.Y. Wheat cell number regulator CNR10 enhances the tolerance, translocation, and accumulation of heavy metals in plants. Environ. Sci. Technol. 2019, 53, 860-867. [CrossRef] [PubMed]

43. Qiao, K.; Wang, F.H.; Liang, S.; Wang, H.; Hu, Z.L.; Chai, T.Y. New biofortification tool: Wheat TaCNR5 enhances zinc and manganese tolerance and increases zinc and manganese accumulation in rice grains. J. Agric. Food Chem. 2019, 67, 9877-9884. [CrossRef]

44. Wan, D.L.; Li, R.L.; Zou, B.; Zhang, X.; Cong, J.Y.; Wang, R.G.; Xia, Y.J. Calmodulin-binding protein CBP60g is a positive regulator of both disease resistance and drought tolerance in Arabidopsis. Plant Cell Rep. 2012, 31, 1269-1281. [CrossRef] [PubMed]

45. Sunkar, R.; Kaplan, B.; Bouche, N.; Arazi, T.; Dolev, D.; Talke, I.N.; Maathuis, F.J.M.; Sanders, D.; Bouchez, D.; Fromm, H. Expression of a truncated tobacco NtCBP4 channel in transgenic plants and disruption of the homologous Arabidopsis CNGC1 gene confer $\mathrm{Pb}^{2+}$ tolerance. Plant J. 2000, 24, 533-542. [CrossRef] [PubMed]

46. Kolukisaoglu, H.U.; Bovet, L.; Klein, M.; Eggmann, T.; Geisler, M.; Wanke, D.; Martinoia, E.; Schulz, B. Family business: The multidrug-resistance related protein (MRP) ABC transporter genes in Arabidopsis thaliana. Planta 2002, 216, 107-119. [CrossRef]

47. Zientaraa, K.; Wawrzynska, A.; Łukomskaa, J.; López-Moya, J.R.; Liszewska, F.; Assuncão, A.G.L.; Aarts, M.G.M.; Sirko, A. Activity of the AtMRP3 promoter in transgenic Arabidopsis thaliana and Nicotiana tabacum plants is increased by cadmium, nickel, arsenic, cobalt and lead but not by zinc and iron. J. Biotechnol. 2009, 139, 258-263. [CrossRef]

48. Cui, E.P.; Cui, B.J.; Fan, X.Y.; Li, S.J.; Gao, F. Ryegrass (Lolium multiflllorum L.) and Indian mustard (Brassica juncea L.) intercropping can improve the phytoremediation of antibiotics and antibiotic resistance genes but not heavy metals. Sci. Total Environ. 2021, 784, 147093. [CrossRef]

49. Pfaffl, M.W.; Horgan, G.W.; Dempfle, L. Relative expression software tool (REST) for group-wise comparison and statistical analysis of relative expression results in real-time PCR. Nucleic Acids Res. 2002, 30, e36. [CrossRef] [PubMed] 